\title{
POLÍTICAS DE EDUCAÇÃO ESPECIAL E EDUCAÇÃO SUPERIOR: Acesso e permanência para estudantes com deficiência em uma universidade federal
}

\author{
CARINA ELISABETH MACIEL \\ Universidade Federal do Mato Grosso do Sul - UFRMS. ORCID: https://orcid.org/0000-0003-3765- \\ 3139. E-mail: carina22em@gmail.com
}

\section{ADRIANA APARECIDA BURATO MARQUES BUYTENDORP}

Secretaria da Educação do Mato Grosso do Sul. ORCID: https://orcid.org/0000-0001-6805-6949.

E-mail: adribuy@uol.com.br

\section{STÉFANI QUEVEDO DE MENESES}

Secretaria da Educação do Mato Grosso do Sul. ORCID: https://orcid.org/0000-0002-5108-1651.

E-mail: stefani.m.quevedo@gmail.com 


\section{RESUMO}

Este artigo tem como objetivo analisar políticas destinadas a favorecer o acesso e a permanência de estudantes com deficiência em uma Universidade Federal. A Instituição analisada, adota a política de cotas para pessoas com deficiência, desde o ano de 2017, no entanto já desenvolve ações para favorecer a permanência, deste público-alvo, há mais tempo. O resgate legislativo atrelado a retomada cronológica de incentivo a permanência de acadêmicos com deficiência, teve como destaque o ano de 2008, no qual foi ratificada a Política Nacional de Educação Especial na Perspectiva da Educação Inclusiva. Para a realização da pesquisa documental utilizamos Relatórios de Gestão e dados estatísticos de estudantes ingressantes e concluintes, de modo a evidenciar informações sobre o público em questão. Também fizemos uso de outros documentos institucionais, como o Plano de Desenvolvimento Institucional (PDI) e o Plano Pedagógico Institucional (PPI), a fim de elucidar relações entre a prédica e a prática da inclusão educacional. $\mathrm{O}$ fortalecimento do Atendimento Educacional Especializado e a organização dos dados sobre os estudantes com deficiência, são destacados como elementos determinantes para a ampliação do acesso e da permanência de estudantes público-alvo da educação especial na educação superior. A imprecisão do número de pessoas com deficiência, dentro da Instituição de Educação Superior, refreia o acompanhamento desses estudantes, por conseguinte, compromete o atendimento de suas reais necessidades. Verificou-se que as ações efetivadas pela divisão responsável por prestar atendimento a esse público, representam avanço no que se refere ao atendimento destes estudantes, entretanto, tais ações precisam ser ampliadas e institucionalizadas, consequentemente adquirindo assim, maior notoriedade na seara acadêmica, para que possam resultar na expressiva execução das atividades apontadas nos relatórios, implicando em avaliações alternativas, bem como adequação didática e demais intervenções no currículo, como também orientações acerca das particularidades de cada deficiência in loco, que considerem as singularidades de cada estudante, para de fato fomentar um currículo acessível e significativo, que atinja não apenas resultados para uma vida acadêmica, mas que possam contribuir com o sentimento de pertença social desses sujeitos.

Palabras Chaves: Política de Educação Superior. Educação Especial. Estudante com Deficiência.

\section{SPECIAL EDUCATION AND COLLEGE EDUCATION POLICIES: ACCESS AND PERMANENCE FOR STUDENTS WITH DISABILITY AT A FEDERAL UNIVERSITY}

This article aims to analyze policies aimed at favoring the access and permanence of students with disabilities at a Federal University. The Institution analyzed adopts the quota policy for people with disabilities, since 2017, but has already developed actions to favor the permanence of this target group, for a longer period. The legislative rescue linked to the chronological resumption of incentive for the permanence of academics with disabilities was highlighted in 2008, in which the National Policy on Special Education in the Perspective of Inclusive Education was ratified. For the accomplishment of the documentary research we used Management Reports and statistical data of incoming and conclusive students, in order to show information about the public in question. We also made use of other institutional documents, such as the Institutional Development Plan (IDP) and the Institutional Pedagogical Plan (IPP), 
in order to elucidate relations between preaching and the practice of educational inclusion. The strengthening of the Specialized Educational Assistance and the organization of the data about students with disabilities are highlighted as determinants for the expansion of the access and permanence of students targeted group of special education in college education. The imprecision of the number of people with disabilities within the College Education Institution, restrains the monitoring of these students, therefore, compromises the attendance of their real needs. It was verified that the actions carried out by the division responsible for attending this public, represent progress in the attendance of these students, however, such actions need to be expanded and institutionalized, consequently acquiring greater awareness in the academic field, so that may result in the expressive execution of the activities indicated in the reports, implying alternative assessments, as well as didactic adequacy and other interventions in the curriculum, as well as guidelines on the particularities of each disability in loco, that consider the singularities of each student, in order to foment an accessible and meaningful curriculum that not only achieves results for an academic life, but which can contribute to the sense of social belonging of these subjects.

Keywords: College Education Policy. Special education. Student with disability.

\section{POLÍTICAS DE EDUCACIÓN ESPECIAL Y EDUCACIÓN SUPERIOR: ACCESO Y PERMANENCIA PARA ESTUDIANTES CON DISCAPACIDAD EN UNA UNIVERSIDAD FEDERAL}

Este artículo tiene como objetivo analizar políticas destinadas a favorecer el acceso y la permanencia de estudiantes con discapacidad en una Universidad Federal. La Institución analizada, adopta la política de cuotas para personas con discapacidad, desde el año 2017, pero ya desarrolla acciones para favorecer la permanencia, de este público que mira, hace más tiempo. El rescate legislativo vinculado a la recuperación cronológica de incentivo a la permanencia de académicos con discapacidad, tiene como destaque el año 2008, en el cual fue ratificada la Política Nacional de Educación Especial en la Perspectiva de la Educación Inclusiva. Para la realización de la investigación documental utilizamos Informes de Gestión y datos estadísticos de estudiantes ingresantes y concluyentes, para evidenciar informaciones sobre el público en cuestión. También hicimos uso de otros documentos institucionales, como el Plan de Desarrollo Institucional (PDI) y el Plan Pedagógico Institucional (PPI), a fin de elucidar relaciones entre la predicación y la práctica de la inclusión educativa. El fortalecimiento de la Atención Educativa Especializada y la organización de los datos sobre los estudiantes con discapacidad, son destacados como elementos determinantes para la ampliación del acceso y la permanencia de estudiantes público objetivo de la educación especial en la educación superior. La imprecisión del número de personas con discapacidad, dentro de la Institución de Educación Superior, refrena el acompañamiento de esos estudiantes, por lo tanto, compromete la atención de sus reales necesidades. Se verificó que las acciones efectivas por la división responsable por prestar atención a ese público, representan avance en lo que se refiere a la atención de estos estudiantes, sin embargo, tal acciones necesitan ser ampliadas e institucionalizadas, consecuentemente adquiriendo así mayor notoriedad en la escuela académica, para que puedan resultar en la expresiva ejecución de las actividades señaladas en los informes, implicando en evaluaciones alternativas, así como adecuación didáctica y demás intervenciones en el currículo, así como orientaciones sobre las particularidades de cada discapacidad in loco, que consideren las singularidades de cada estudiante, para de hecho fomentar un currículo accesible y significativo, que llegar no sólo resultados para una vida académica, pero que puedan contribuir con el sentimiento de pertenencia social de esos sujetos.

Palabras clave: Política de Educación Superior. Educación Especial. Estudiante con discapacidad. 


\section{POLÍTICAS DE EDUCAÇÃO ESPECIAL E EDUCAÇÃO SUPERIOR: Acesso e permanência para estudantes com deficiência em uma universidade federal}

\section{Introdução}

Este texto tem como objetivo analisar políticas destinadas a favorecer o acesso e a permanência de estudantes com deficiência em uma Universidade Federal ${ }^{1}$. A Educação Superior Pública Federal apresentou na última década uma expansão importante nas matrículas, inclusive nas de estudantes com deficiência. Entretanto, as ações destinadas aos estudantes com deficiência, ainda estão em desenvolvimento, conforme apontam algumas pesquisas (MACIEL; ANACHE, 2017).

Ampliar o acesso e permanência à educação consiste em um processo ainda em desenvolvimento, que traz consigo um caráter específico, tanto na educação básica, como na Educação Superior. A Política Nacional de Educação Especial na Perspectiva da Educação Inclusiva de 2008 preconiza vários Atendimentos Educacionais Especializados (AEE) para garantir a permanência de estudantes com deficiência na educação básica. Esse mesmo documento indica a necessidade do AEE para esse grupo de estudantes na Educação Superior também. A educação básica tem seu acesso como "obrigatório" à todos, inclusive às pessoas com deficiência; já a educação superior apresenta um gargalo para o acesso às Instituições desse nível de educação: os processos de seleção.

A Política de Cotas (13.409/2016²) compreende entre os grupos dessa ação, pessoas com deficiência, favorecendo assim, oportunidades de acesso à educação superior para estudantes desse grupo. Entretanto, as ações de permanência ainda estão sendo elaboradas para atender essa legislação publicada em 2016. O AEE na educação superior ainda encontra obstáculos importantes, inclusive falta de profissionais para atender esses estudantes na educação superior.

Para investigarmos elementos sobre a permanência de estudantes com deficiência na educação superior, elencamos uma Universidade Federal que adota a Política de Cotas para esse

\footnotetext{
${ }^{1}$ A Universidade Federal investigada não será divulgada por questões éticas.

${ }^{2}$ Altera a Lei No 12.711, de 29 de agosto de 2012 (BRASIL, 2016).
}

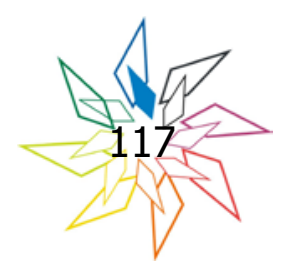


grupo, desde o ano de 2017. Como dados empíricos, utilizamos Relatórios de Gestão e números de acadêmicos ingressantes e concluintes, que possam indicar nexos ou os efeitos das políticas vigentes. A pesquisa configura-se em caráter exploratório, em consonância com Gil (2002, p.41): "estas pesquisas tem como objetivo proporcionar maior familiaridade com o problema, com vistas a torna-lo mais explícito". Evidencia-se também o cunho documental, pautando-se no levantamento de dados estatísticos e institucionais.

Não há como pensar em educação superior sem pontuar seu envolvimento na produção do conhecimento científico e técnico, a qual tem contribuído de forma veemente, na continuidade do processo capitalista que proporciona sua legitimidade por intermédio do currículo, seja ele, explícito ou implícito, fato que lhe apregoa um corolário acumulativo (SILVA, 1996). Nesse viés entende-se que a hegemonia educacional requer dos sujeitos que pleiteiam uma vaga nas universidades, saberes que venham corroborar com a constante produção, porém, nem todos os partícipes desse processo, irão produzir a contento das expectativas desse molde, no entanto, poderão apresentar habilidades que só serão evidenciadas a partir de uma ótica verdadeiramente subjetiva.

A história da educação de pessoas com deficiência é determinada por situações de exclusão social e de discriminações negativas, mas também, por lutas e conquistas em uma sociedade em que o mérito consiste em um elemento determinante. Nessa perspectiva, para Gramsci (1978) a possibilidade não significa precisamente a realidade, porém, torna-se real que o homem possa ou não realizar uma ação, superando sua condição inicial por meio de novos conhecimentos.

Nesse texto trabalhamos com a definição de educação especial de acordo com a Lei de Diretrizes e Bases Nacional (LDB/1996), publicada em dezembro de 1996 em seu Capítulo V:

Art. 58. Entende-se por educação especial, para os efeitos desta Lei, a modalidade de educação escolar oferecida preferencialmente na rede regular de ensino, para educandos com deficiência, transtornos globais do desenvolvimento e altas habilidades ou superdotação (Redação dada pela Lei $\mathrm{n}^{\mathrm{o}}$ 12.796, de 2013).

$\S 1^{\circ}$ Haverá, quando necessário, serviços de apoio especializado, na escola regular, para atender às peculiaridades da clientela de educação especial. 
Com base no grupo de pessoas atendidas pela educação especial, destacamos as pessoas com deficiência, uma vez que estas serão público-alvo da política de cotas para ingresso na educação superior.

\section{Políticas Públicas de Inclusão na Educação Superior}

A palavra "inclusão" tem sido bastante recorrente em discussões e, na medida em que é proferida, relações sociais resultantes das políticas que se alicerçam nessa predicação despontam a organização dessa sociedade, que modificam as relações, mesmo que paulatinamente. Evidenciase que o discurso da inclusão seja consequente das relações que a sociedade civil alimenta com o Estado, garantindo a solidificação de políticas públicas, em especial, as políticas sociais de educação, concomitantemente, transformando-as (MACIEL \& URQUIZA, 2017).

Por conseguinte, tem-se a necessidade de vislumbrar a inclusão no que se refere a acesso e permanência. Nesse sentido é valido salientar que de modo geral, a categoria permanência na educação superior desponta no Brasil posteriormente ao aumento de cursos e instituições nos anos de 1990 no setor privado, por intermédio da instauração de políticas públicas que cerceassem à expansão da educação superior nas instituições públicas, a partir dos anos 2000 (ALMEIDA, 2009).

Um pressuposto de investigação do itinerário das Políticas de Inclusão para a Educação Superior (2008) precisa adotar, mesmo que brevemente, um resgate dos dispositivos que antecedem a Política Nacional de Educação Especial na Perspectiva da Educação Inclusiva, dessa forma, para conduzir a priori, a estruturação deste estudo Maciel \& Anache (2017, p.71) contribuem:

\footnotetext{
O Programa Incluir foi desenvolvido pela Secretaria de Ensino Superior (SESU) em parceria com a Secretaria de Educação Especial (SEESP). O programa é voltado para a inclusão de pessoas com deficiência na educação superior em cumprimento ao Decreto $n^{\circ} 5.296 / 2004$. (BRASIL, 2004). No Governo de Dilma Rousseff, a parceria é realizada por meio da Secretaria de Educação Superior (SESU) e da Secretaria de Educação Continuada, Alfabetização, Diversidade e Inclusão (SECADI). Já em 2006 foi assinado o Decreto n ${ }^{\circ}$.773, que estabelece normas para as funções de regulação, supervisão e avaliação das instituições de educação superior, e o Projeto de Lei $n^{0} 7.200 / 2006$, que estabelece nova regulamentação para a educação superior brasileira.
}

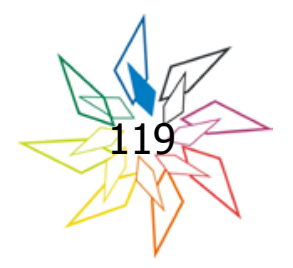


Foi lançado oficialmente, em 24 de abril de 2007, o Plano de Desenvolvimento da Educação (PDE), que trata dos objetivos e das ações para os diferentes níveis e modalidades da educação brasileira. O PDE da educação superior elege os seguintes princípios: expansão da oferta de vagas; garantia de qualidade, promoção de inclusão social, ordenação territorial; desenvolvimento econômico e social. Nele, o Programa de Apoio aos Planos de Reestruturação e Expansão das Universidades Federais (REUNI) [...].

Vale pontuar que o Plano de Reestruturação e Expansão das Universidades Federais (REUNI) não aduz diretamente estudantes com deficiência, uma vez que objetiva a igualdade de oportunidades para discentes que apresentam condições socioeconômicas desfavoráveis, inferindo que tal medida está agregada a inclusão, democratização de acesso e permanência (BRASIL, 2007).

Fazem-se perceptíveis ações governamentais que se direcionem a seara educacional com propostas que possam oferecer suporte para a inclusão de pessoas com deficiência na educação superior, porém, essas ainda se encontravam em processo de expansão e consolidação. Até aquele momento não se podia depreender que havia um preparo efetivo das Instituições Federais de Educação Superior (IFES), para atender as especificidades desses sujeitos, uma vez que tal prática demanda recursos para possibilitar reestruturação do espaço físico, Ajudas Técnicas ou Tecnologias Assistivas, profissionais especializados para atender as demandas subjetivas desse público na adequação de materiais didáticos, dentre outros.

A Convenção dos Direitos das Pessoas com Deficiência proposta pela Assembleia Geral da Organização das Nações Unidas (ONU, 2006), com seu Protocolo Facultativo assinado em Nova York no ano de 2007, foi ratificada ${ }^{3}$ no Brasil em junho de 2008, estabelecendo o compromisso do Estado em cumprir as ações previstas no documento supracitado, afirmando seu caráter obrigatório com a publicação do Decreto 186/2008. Tal decreto torna-se emenda constitucional, evidentemente estende sua determinação, a qual prevê que quaisquer leis que amparam os direitos das pessoas com deficiência precisarão principiar-se em seu conteúdo, caso contrário, resultarão em pena de anulação em decorrência da inconstitucionalidade.

Destarte, a Política Nacional de Educação Especial na Perspectiva da Educação Inclusiva tem como sustentáculo o Decreto 186/2008, porém não menos importante que este, uma vez que

${ }^{3}$ Em agosto de 2009 surge o Decreto de Promulgação № 6.949/2009 (BRASIL, 2009). 
possibilita a continuidade das lutas pelos direitos da pessoa com deficiência, surge como um farol, que tem por objetivo rumar ações das políticas brasileiras vindouras. É imprescindível inferir que tal documento salienta em sua introdução, a relação atrelada entre a Educação Inclusiva e os Direitos Humanos apresentando como propósito a equidade:

O movimento mundial pela inclusão é uma ação política, cultural, social e pedagógica, desencadeada em defesa do direito de todos os alunos de estarem juntos, aprendendo e participando, sem nenhum tipo de discriminação. A educação inclusiva constitui um paradigma educacional fundamentado na concepção de direitos humanos, que conjuga igualdade e diferença como valores indissociáveis, e que avança em relação à ideia e equidade formal ao contextualizar as circunstâncias históricas da produção da exclusão dentro e fora da escola (BRASIL, 2008).

Na concepção do trabalho educativo referido por Saviani (1991) notabiliza-se como o ato de produzir, direta e intencionalmente, de modo singular a cada indivíduo, a humanidade que tem sua produção histórica e coletiva pelo conjunto de homens. Por conseguinte, a educação apresenta como intento de um lado, à identificação dos elementos culturais, que precisam ser compreendidos pelos sujeitos da espécie humana, de modo que eles se tornem humanos, e de outro lado, simultaneamente, descobre-se as estratégias mais pertinentes para atingir tal objetivo.

É sabido que os valores econômicos empregados pela sociedade hodierna influenciam diretamente na estruturação educacional, em que se costuma primar por um mero condicionamento, que muitas vezes, é escamoteado por falsas práticas de inclusão. Possibilitar mão de obra para o mercado em atividades mecânicas costuma ser o destino de muitos sujeitos com deficiência, uma vez que a consolidação de uma realidade que estruture condições que vão além dos muros da escola regular, ainda vem ganhando formas.

A Política Nacional de Educação Especial na Perspectiva da Educação Inclusiva, também pontua a necessidade de pensar em direitos de uma educação contínua, para que se possa disponibilizar não apenas o que se considera básico, uma vez que tal fator pode não suprir as necessidades de um sujeito. Conquanto, tal política objetiva:

[...] assegurar a inclusão escolar de alunos com deficiência, transtornos globais do desenvolvimento e altas habilidades/superdotação, orientando os sistemas de ensino para garantir: acesso ao ensino regular, com participação, aprendizagem e continuidade nos níveis mais elevados do ensino; transversalidade da modalidade de educação especial desde a educação infantil

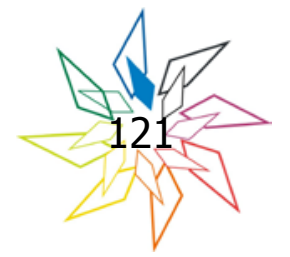


até a educação superior; oferta do atendimento educacional especializado; formação de professores para o atendimento educacional especializado e demais profissionais da educação para a inclusão; participação da família e da comunidade; acessibilidade arquitetônica, nos transportes, nos mobiliários, nas comunicações e informação; e articulação intersetorial na implementação das políticas públicas (BRASIL, 2008).

É indispensável frisar que de acordo com o documento supramencionado, a organização de recursos e serviços que promovem a acessibilidade arquitetônica, comunicacional, bem como inseridos nos materiais didáticos e pedagógicos, apresentam caráter impreterível para a disponibilização destes nos processos seletivos que possibilitam ingresso à educação superior (BRASIL, 2008).

Quando as problemáticas concernentes a Educação Especial entram em voga, na maioria dos casos, os grandes focos de discussão discorrem acerca dos anos iniciais até o ensino médio, há uma acentuada preocupação social para garantir o que a grande maioria compreende como o essencial, para o futuro dos sujeitos que, vez em quando entram no esquecimento da grande massa, aqueles que apresentam deficiências, diversas vezes, lembrados em formações pedagógicas, quando crianças ou quando o assunto discorre em torno da acessibilidade, rampas de acesso, corrimãos, piso tátil, dentre outros. Tais fatores são bastante importantes, porém, insuficientes para abranger o que deveras se apresenta como essencial. Antes de visualizar uma deficiência fazse necessário identificar um ser humano, que possui potencialidades e limitações e que poderá carregar consigo projetos de vida, que não são apenas supridos pela educação básica.

Faz-se imprescindível analisar a fundamentação do conhecimento, será ele o elemento substancial para transformar em realidade o ideal de emancipação humana, conjuntamente com a dedicação dos indivíduos para alcançar a "autoemancipação" da humanidade, apesar dos entraves ali encontrados, ou será, em contrapartida, a adoção dos indivíduos, em particular, por comportamentos que apenas favorecem a realização de metas objetivadas no capital? (MÉSZÁROS, 2005).

Sequencialmente no ano de 2010, há o Decreto $\mathrm{N}^{\circ} 7.234$, que dispõem acerca do Programa Nacional de Assistência Estudantil - PNAES, o qual tem por objetivo democratizar as condições de permanência dos jovens na Educação Superior Pública Federal, minimizando os efeitos das desigualdades sociais e regionais na permanência e conclusão da educação superior, para que também possa reduzir as taxas de retenção e evasão; corroborando para a promoção da inclusão social pela educação. É imprescindível pontuar que o artigo $3^{\circ},\left(\S 1^{\circ}\right)$ tem por finalidade 
desenvolver ações como: "o acesso, participação e aprendizagem de estudantes com deficiência transtornos globais do desenvolvimento e altas habilidades e superdotação" (BRASIL, 2010).

Em 2011, os núcleos de acessibilidade nas Instituições Federais de Educação Superior (IFES) tem sua estruturação apresentada com o Decreto $N^{\circ} 7.611$, referindo-se a Educação Especial à luz do Atendimento Educacional Especializado, que em seu artigo $5^{\circ}$ apresenta a funcionalidade de tais núcleos que preveem a eliminação de barreiras físicas, sejam elas comunicacionais ou informacionais, que porventura possam limitar a integração e evoluções acadêmicas e sociais do educando com deficiência (BRASIL, 2011).

Com demais contribuições é possível analisar os reveses para a efetivação das políticas de inclusão:

A inclusão da pessoa com deficiência no ensino superior vem ocorrendo gradativamente. Isso decorre, dentre outros fatores, pela pequena parcela da população ter acesso à educação básica e aos serviços de reabilitação o que indica sua exclusão dos direitos sociais básicos. Associado a isso, é possível afirmar que as restrições de acesso e progressão dessas pessoas na educação superior estão relacionadas as condições socioeconômicas e à própria história de exclusão, peculiar a educação superior no país, com forte tendência à privatização, ao elitismo, como também ao mito de incapacidade creditado à pessoa com deficiência (MIRANDA, 2011, p.120).

Evidencia-se o dever das Instituições de Educação Superior no que se refere a proporcionar sendas para que os direitos do acesso à educação sejam equânimes. Dessa forma, pode-se evidenciar que o aumento das matrículas de pessoas com deficiência, o qual será apresentado mais adiante, decorre dos dispositivos que salvaguardam o acesso e a permanência, requerendo um atendimento singular, que leve em conta as limitações de cada estudante e que possa auxiliar no rompimento de barreiras, para que o conhecimento adentre ao caráter plural reduzindo a possibilidade de evasão acadêmica. 


\section{Acesso e permanência de estudantes com deficiência em uma universidade federal}

Desde o início dos anos 2000, as políticas de educação superior têm sido determinadas por metas e objetivos governamentais que priorizam o acesso e a permanência de estudantes em IES públicas (ALMEIDA, 2009). A política de cotas consiste em uma ação afirmativa que, a partir de 2016, destina parcela das vagas em Universidades Federais para pessoas com deficiência.

Nesse sentido, notabiliza-se a necessidade da criação de programas e ações institucionais que possibilitem respaldo aos estudantes com deficiência, inseridos em um contexto que prime pela igualdade de direitos

Talvez seja mais correcto designar a área do acesso como acesso/permanência ou mesmo acesso/permanência/sucesso, uma vez que o que está em causa é garantir, não só o acesso, mas também a permanência e o sucesso dos estudantes oriundos de classes ou grupos sociais discriminados (SANTOS, 2005, p.68-69).

O Plano de Desenvolvimento Institucional (PDI) da Universidade investigada, com extensão ao ano de 2015 a 2019, apresenta propostas de incentivo que abarcam investimentos para ações de acesso, permanência e conclusão de curso, destinadas aos sujeitos que venham apresentar impedimentos físico, sensoriais, mentais/intelectuais, múltiplas deficiências, transtornos mentais, incluindo também pessoas com altas habilidades/superdotação objetivando:

- Acompanhar o ingresso, permanência e conclusão dos discentes, visando a lhes proporcionar os apoios educacionais necessários para o sucesso acadêmico;

- Fomentar a articulação dos diferentes setores e áreas de formação [...] com a finalidade de promover condições de ensino, pesquisa e extensão na perspectiva da inclusão;

- Realizar ações que objetivem eliminar as barreiras de natureza arquitetônica, comunicacional, pedagógica, instrumental, legal (políticas) e atitudinal;

- Contribuir na atualização e elaboração dos projetos pedagógicos dos cursos de graduação com conteúdos ou disciplinas que abordam assuntos relacionados 
às necessidades educacionais dos estudantes que apresentam algum tipo de impedimento físico, sensorial, mental/intelectual, deficiências múltiplas, transtornos mentais, bem como aqueles com altas habilidades/superdotação;

- Fomentar ações com a Pró-Reitoria de Gestão de Pessoas para propiciar condições de acessibilidades para os profissionais que apresentam deficiências (PDI, 2015-2019).

Vale destacar a existência de uma Divisão específica que iniciou suas atividades no ano de 2013, e tem por objetivo o acompanhamento de estudantes com deficiência, como também prestar assistência aos estudantes que ingressaram por meio da política de cotas, até então estudantes: indígenas, pretos, pardos e quilombolas na referida instituição. A partir de 2017, estudantes com deficiência também consistem público da Política de Cotas.

Nas considerações do relatório de atividades da Divisão (2015) consta a conjectura de desmembramento da divisão, de modo que possam ser criados Núcleos de Acessibilidade para a Universidade, como prescreve a legislação oficial (Decreto $\mathrm{N}^{0}$ 7.611), com a intenção de instaurar outro Núcleo para atender estudantes que ingressaram pela política de cotas, requerendo também, profissionais capacitados para atender as diferentes necessidades dos grupos específicos. Contudo, ainda não houve publicação de conhecimento, que afirme a realização do desmembramento da divisão.

A Divisão realiza Atendimento Educacional Especializado (AEE) tendo como aparato legal o Decreto ${ }^{4} \mathrm{~N}^{\mathrm{o}} 7.611 / 2011$, que assegura a educação especial, o atendimento educacional especializado, que no artigo $3^{\circ}$ determina a transversalidade das ações da educação especial no ensino regular, e como referido anteriormente, prevê a estruturação dos núcleos de acessibilidade nas IFES (BRASIL, 2011).

Santana (2016) assevera que o AEE tem como mote a identificação das necessidades educacionais de acadêmicos que pertencem ao público alvo da Educação Especial, vislumbrando o rompimento de barreiras físicas de comunicação e informação impeditivas na participação acadêmica e social. Também infere sobre a execução de entrevista semiestruturada, que

\footnotetext{
${ }^{4}$ O Decreto 6.571/2008 que antecedeu tal dispositivo foi revogado, sendo substituído pelo decreto em questão (BRASIL, 2008).
}

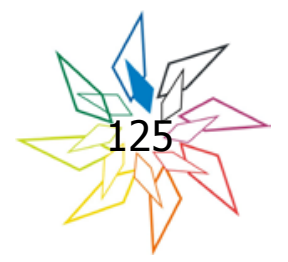


coaduna com a identificação das necessidades do acadêmico e na sequência, há o planejamento de atendimentos que possam contribuir para o processo de aprendizagem.

Por meio do Relatório de Trabalho da Divisão, evidenciam-se as ações do AEE na Universidade caracterizando-se por:

a) Adaptação de recursos pedagógicos;

b) Adaptação de recursos pedagógicos para o público alvo da educação especial e disponibilizar softwares, tecnologias assistivas e outros;

c) Subsidiar as mudanças curriculares necessárias para proporcionar condições educacionais ao público alvo da educação especial;

d) Orientar os coordenadores, professores e funcionários, visando proporcionar condições educacionais ao público alvo da educação especial.

e) Orientar as ações relacionadas às mudanças arquitetônicas e mobiliárias, visando proporcionar condições de acesso nos diversos ambientes [...];

f) Assessorar os órgãos gestores sobre assuntos pertinentes à educação do público alvo da educação especial nos cursos [...];

g) Promover eventos que orientem a comunidade universitária sobre as necessidades educacionais do público alvo da educação Especial;

h) Articular ações que articulem o ensino, a pesquisa e a extensão na perspectiva da educação inclusiva (DIVISÃO, 2015).

\section{Currículo e Educação Superior}

Não há como vislumbrar o processo estrutural do currículo como unicamente lógico, porém, deve ser visto como um processo social que se constrói conjuntamente com fatores lógicos e epistemológicos, assim como determinantes sociais, como interesses, rituais e conflitos 
simbólicos e culturais, impregnado de necessidades de legitimação e controle interligados por fatores de classe, raça e gênero. Todavia, não se pode entender o currículo como um fornecedor de conhecimentos válidos, mas de conhecimentos socialmente válidos (SILVA, 1996).

Dessa forma, Luckesi (2005) traz à tona alguns conceitos resultantes da avaliação a qual costuma substanciar e aferir a hipotética absorção curricular com os seguintes apontamentos:

- O ato de avaliar parte da construção da acolhida, a disposição para acolher é o ponto de partida para qualquer avaliação;

- O ato de avaliar implica dois processos indissociáveis: diagnosticar e decidir;

- A capacidade de escolha implica seleção de instrumentos adequados para realizar a avaliação: "Muitas vezes, nossos educandos são competentes em suas habilidades, mas nossos instrumentos de coleta de dados são inadequados e, por isso, os julgamos, incorretamente, como incompetentes" (LUCKESI, 2000, p.10).

Buytendorp (2006) atesta que o currículo apresenta complexidade em seu sentido prático, sendo apresentado por diferentes óticas, assumindo papel socializador e cultural de uma instituição específica, consolidando as funções do próprio âmbito escolar à luz de um momento histórico, por conseguinte, faz-se instrumento, estruturado pelos sistemas educacionais, que se modelam em consonância dos interesses concretos, nos quais metas são transformadas em estratégias de ensino, que atendam a conflitos e interesses, exercendo papéis diversos, em cada nível de ensino.

Depreende-se, dessa forma, que o currículo representa uma sequência de conteúdos que devem ser cumpridos em vista das exigências de cada um dos níveis educacionais, sejam da educação básica ou do âmbito acadêmico.

Manjón (1995) refere que a necessidade educacional especial pode tomar diferentes formas. Nesse aspecto poderá implicar na provisão de meios especiais de acesso ao currículo, por intermédio de equipamentos ou de técnicas de ensino especializadas; até mesmo, podendo referir-se da necessidade de modificar o currículo, ou da imprescindibilidade de uma atenção particular ao contexto social e ao clima emocional, os quais se desenvolvem a educação.

Fazendo remissão novamente ao PDI (2015-2019) da Universidade, acerca do currículo tal documento estabelece:

plullais Salvador, v.3, n.3, p. 114- 135, set./dez. 2018

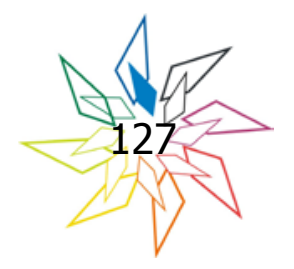


[...] ações que têm por intuito a construção de currículos que atendam a diversidade das características educacionais dos estudantes que apresentam algum tipo de impedimento físico, sensorial, mental/intelectual, deficiências múltiplas, transtornos mentais, bem como aqueles com altas habilidades/ superdotação, garantindo-lhe o acesso, a permanência e o máximo de autonomia para concluírem o curso de ensino superior. Portanto, a proposta curricular destes cursos deverá respeitar a diversidade dos ritmos de aprendizagem destes alunos, valorizando as suas experiências acadêmicas e não acadêmicas, possibilitando-lhes condições de ensino aprendizagem.

[...] tem por finalidade promover orientações e cursos em diversos níveis que visem ao desenvolvimento de práticas educacionais inclusivas e para o uso da Língua Brasileira de Sinais, Tradutor ou Interprete de leitura do sistema Braille, serviços de áudio descrição e profissionais que atuam com tecnologias assistivas (PDI 2015-2019).

O Plano Pedagógico Institucional (PPI, 2009) da Universidade pesquisada versa sobre o currículo empregando-lhe o processo de ensinar e aprender instrumentado no diálogo, participação e integração do conhecimento com viés democrático e compromissado com cada partícipe. Apresenta-se também, o currículo, pela ótica do ensino e aprendizagem como processo humano, o que implica em docentes e discentes que se coloquem como atores sociais, políticos e culturais que demarquem o currículo em território de formação plural e dinâmica.

A instituição em questão reconhece a necessidade de contemplar diferentes ritmos de aprendizagem, sendo fornecedora de amparos que garantem a autonomia dos acadêmicos, bem como profissionais da área de tecnologia assistiva, portanto, não há motivos para considerar que a presente instituição negligencie o processo avaliativo dos estudantes, levando em conta a disposição das diretrizes vigentes.

\section{Estudantes com Deficiência na Universidade}

Para a fundamentação das análises, optou-se inicialmente pela pesquisa dentro do site da Universidade Federal investigada, na procura por dados via Relatórios de Gestão publicados, que pudessem descrever as principais ações que se concretizaram na Universidade investigada. 
No Relatório de Gestão de 2008 foi registrado em seu Objetivo 4: Ampliar programas de educação continuada, em parceria com entidades governamentais e de classe. A Meta - 2 tem o objetivo de incentivar a participação de docentes em programas de educação continuada. Apresentou-se como evento realizado - "Curso de Capacitação Educar na Diversidade: Deficiência Mental e Processos Educativos" (RELATÓRIO DE GESTÃO, 2008, p.122). Já em 2009, há referência sobre Educação Especial no relatório dentro do Objetivo 3: Aperfeiçoar o Programa Nacional de Fomento à Extensão e Atendimento Estudantil na Instituição. Na meta 4: Criar e aperfeiçoar Programas de Assistência Estudantil - registra como realização no ano, a elaboração e aprovação a ação de extensão: "Universidade Acessível - estratégias para inclusão de acadêmicos com deficiência na Universidade" (RELATÓRIO DE GESTÃO, 2009, p. 90).

No ano de 2010 dentro das ações desenvolvidas, porém, não previstas pelo Plano de Desenvolvimento Institucional (PDI) refere-se à Modernização e Dinamização do sistema da Biblioteca, sendo disponibilizado um computador para consulta com programa específico para deficiência visual (RELATÓRIO DE GESTÃO, 2010, p. 205). Em 2011 na Diretriz 5 - que se refere ao Compromisso Social da Instituição, dentro do programa de apoio ao estudante, registra a realização da pesquisa retrospectiva, descritiva e documental, entre o ano 2009 a 2011, que identifica o número de 167 acadêmicos com algum tipo de deficiência. Tal levantamento foi realizado para posteriormente possibilitar atendimento (RELATÓRIO DE GESTÃO, 2011, p. 244).

Tomando como referência da consulta de relatórios os anos 2012 e 2013, o primeiro ano, como meta de apoio ao estudante, apresenta o levantamento anual do número de pessoas com deficiência, identificadas por meio de declaração na matrícula. Com o auxílio de dados fornecidos pela Universidade, indicando o total de 318 estudantes com deficiência entre 2012 e 2013. Após a coleta de dados foi realizada intervenção via telefone, fora possível constatar que a maioria dos estudantes que afirmou possuir baixa visão, não precisava de atendimento especializado e auxílio, uma vez que o uso de lentes corretivas sanava as limitações. Posteriormente houve a construção de um documento com orientações de desenvolvimento de conteúdo aos professores que lidavam com estudantes que apresentavam alguma deficiência. No mesmo ano houve também o surgimento de programas elaborados pela Associação de Pais e Amigos dos Excepcionais (APAE), em convênio com a Universidade, visando à formação para o trabalho sob o regime de estágio profissionalizante supervisionado, para educandos com deficiência mental ${ }^{5}$, com prorrogação de contrato por até 60 meses (RELATÓRIO DE GESTÃO, 2012).

\footnotetext{
${ }^{5}$ Nomenclatura substituída por Deficiência Intelectual (APA. DSM V, 2014).
}

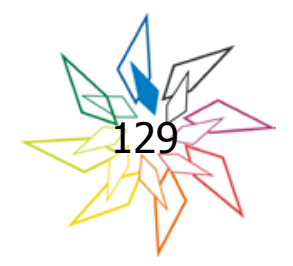


Em 2013, o levantamento do número de estudantes com deficiência identificou 55 discentes. Apenas 5 destes demonstraram necessidade do AEE. Também foram entregues orientações de trabalho aos professores dos referidos estudantes. Nesse período há registros sobre a instauração do Programa de Apoio aos Estudantes, sendo atendidos todos que se encontram em condições de vulnerabilidade, o qual incluiu o público da educação especial, auxiliando nos campos de moradia, alimentação, transporte, assistência à saúde, inclusão digital, cultura, esporte, creche e auxílio pedagógico (RELATÓRIO DE GESTÃO, 2013).

O Relatório de Gestão de 2014 aponta o levantamento anual do número de estudantes com deficiência dentro de suas metas, registrando 212 estudantes. Também dispõem sobre cursos para formação de profissionais acerca das práticas educacionais inclusivas e para o uso da Língua Brasileira de Sinais; Tradutor ou Intérprete de leitura do sistema Braille; serviços de audiodescrição e Tecnologias Assistivas, mudanças arquitetônicas visando à acessibilidade, bem como incentivos de produção de pesquisas no mote da Educação Especial para um evento na Instituição sobre o tema da Inclusão na Educação Superior. Vale ressaltar que essa ação infere sobre as orientações prestadas aos acadêmicos com deficiência e ao corpo pedagógico, já que os docentes da Instituição consistem no público a ser alcançado pelo evento (RELATÓRIO DE GESTÃO, 2014).

O registro do levantamento de estudantes com deficiência em 2015 apresenta o total de 221. A Divisão passa a atender 60 desses estudantes identificados como público-alvo da Educação Especial. Também aponta investimento para aquisição de recursos humanos qualificados para a Divisão, assim como a aquisição de diversos materiais como uma impressora em Braille, 10 calculadoras sonoras, 5 teclados ampliados, dentre outros e a prestação de espaços adaptados (RELATÓRIO DE GESTÃO, 2015).

Em 2016 há uma justificativa sobre os estudantes que declaram ter alguma deficiência, o número apontado foi de 212, apresentando queda em comparação ao ano anterior, por esse motivo, há uma nota esclarecendo, que muitos dos estudantes que declaram ter baixa visão e que apenas fazem uso de óculos, acabam confundindo os termos apresentados nos formulários. No documento também consta a informação de que a Divisão já tentou tomar algumas providências para melhorar o formulário, no entanto, ainda não obteve sucesso. As listas sobre os equipamentos permanentes de acessibilidade também constam no relatório do presente ano, assim como a prestação de contas em relação aos ambientes adaptados. Dentro do relatório há o perfil dos estudantes disposto no quadro abaixo: 
Quadro 1. Perfil dos Acadêmicos com Deficiência

\begin{tabular}{|l|c|}
\hline \multicolumn{1}{|c|}{ Caracteristica do público alvo da Educaçäo Especial } & Quantidade de alunos \\
\hline Deficiência Auditiva & 74 \\
\hline Surdez & 547 - dados em análise \\
\hline Deficiência Visual - Baixa Visão & 0 \\
\hline Surdocegueira & 1 \\
\hline Deficiência Visual - Cegueira & 31 \\
\hline Deficiência Física & 3 \\
\hline Deficiência Intelectual/Mental & 1 \\
\hline Deficiência Múltipla & 0 \\
\hline Síndrome de Asperger & 5 \\
\hline Altas habilidades/ Superdotação & 0 \\
\hline Outros & \\
\hline
\end{tabular}

Fonte: Relatório de Gestão (DIVISÃO, 2015).

Ainda de acordo com o Relatório foram realizados acompanhamentos de 23 acadêmicos com algum tipo de necessidade educacional especial no ano de 2016, totalizando 315 atendimentos (DIVISÃO, 2016). Importante destacar que no Relatório indicam o Perfil do estudante, mas apresentam as deficiências dos mesmos, divididas de acordo com os laudos apresentados.

A partir do quadro anteriormente exposto, evidencia-se a baixa aprovação nos cursos da Instituição no que se refere aos estudantes com Deficiência Intelectual, Autismo, Surdocegueira, o que indica que existem obstáculos a serem vencidos no atendimento durante a realização dos processos seletivos que tiveram a partir de 2009, como principal porta de entrada para a Universidade, o Exame Nacional do Ensino Médio (ENEM), principalmente para o grupo em destaque.

Durante o processo de pesquisa, neste ano (2018) a Divisão providenciou os dados de ingressantes e concluintes com deficiência nos últimos dez anos.

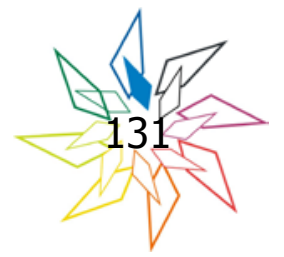


Quadro 2. Total de ingressantes com deficiência nos cursos de graduação 2008-2018

\begin{tabular}{|c|c|}
\hline ANO & INGRESSANTES COM DEFICIÊNCIA \\
\hline 2008 & 92 \\
\hline 2009 & 81 \\
\hline 2010 & 45 \\
\hline 2011 & 215 \\
\hline 2012 & 246 \\
\hline 2013 & 168 \\
\hline 2014 & 232 \\
\hline 2015 & 188 \\
\hline 2016 & 153 \\
\hline 2017 & 192 \\
\hline 2018 & 219 \\
\hline TOTAL & 1.831 \\
\hline
\end{tabular}

Fonte: Divisão (Gerado em 27/03/2018 às 15h15min).

Quadro 3. Total de concluintes com deficiência nos cursos de graduação 2008-2018

\begin{tabular}{|c|c|}
\hline ANO & $N^{\circ}$ CONCLUINTES COM DEFICIÉNCIA \\
\hline 2008 & 0 \\
\hline 2009 & 0 \\
\hline 2010 & 0 \\
\hline 2011 & 0 \\
\hline 2012 & 36 \\
\hline 2013 & 22 \\
\hline 2014 & 19 \\
\hline 2015 & 41 \\
\hline 2016 & 33 \\
\hline 2017 & 29 \\
\hline 2018 & 2 \\
\hline \hline TOTAL & 182 \\
\hline
\end{tabular}

Fonte: Divisão (Gerado em 27/03/2018 às 15h15min) 
Identificamos que de 1.831 (mil oitocentas e trinta e um) estudantes matriculados que declararam apresentar deficiência, apenas 9,92\% concluíram supostamente sua trajetória acadêmica. Após o itinerário dessa pesquisa pode-se deduzir que existem algumas falhas nesses números e que eles também apresentam discrepâncias, tanto com relação as numerações acima, como abaixo das médias apresentadas nas coletas dos relatórios de gestão sequencialmente apresentados. A incoerência entre os dados apresentados acerca da veracidade das informações apontadas nas matrículas, demonstra a urgência no que se refere a identificação e organização dos dados dos estudantes com deficiência na educação superior.

\section{Considerações finais}

Reflexões sobre o acesso, permanência e conclusão de estudantes com deficiência na educação superior trazem consigo inúmeras complexidades. Os investimentos realizados pela União, bem como as propostas de políticas que foram se alicerçando nesses dez anos de aprovação da Política Nacional de Educação Especial na Perspectiva da Educação Inclusiva, notabilizam alguns avanços e esforços, porém ainda é imprescindível cogitar que a organização das informações de matrículas dos estudantes com deficiência, nessa Universidade, resulta em condições que dificultam o atendimento a esse grupo específico.

As ações desenvolvidas na divisão precisam ser institucionalizadas e divulgadas, possibilitando a execução das atividades indicadas nos relatórios como avaliações alternativas e demais intervenções no currículo, assim como as ações in loco, para intervenções curriculares.

Os dados identificados desvelam um processo que já avançou, mas que ainda está em seu início, e que carece de investimento de recursos e de dedicação institucional para que o acesso e a permanência de estudantes com deficiência seja desenvolvido. O fortalecimento do Atendimento Educacional Especializado e a organização dos dados sobre os estudantes com deficiência são destacados como elementos determinantes para a ampliação do acesso e da permanência de estudantes público-alvo da educação especial na educação superior. A elaboração de políticas institucionais que preconizem ações para esse público-alvo consiste em uma das estratégias para o desenvolvimento desse grupo na educação superior.

\section{REFERÊNCIAS}

ALMEIDA, Carina Elisabeth Maciel de. O discurso da inclusão nas políticas de educação superior (2003-2008). 2009. 186f. Tese (Doutorado em Educação) - Programa de Pós Graduação em Educação. Universidade Federal de Mato Grosso do Sul, Campo Grande, 2009.

P/ulais Salvador, v.3, n.3, p. 114- 135, set./dez. 2018

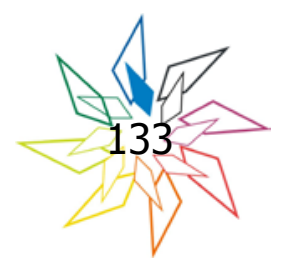


ASSOCIAÇÃO AMERICANA DE PSIQUIATRIA - APA. DSM V - Manual diagnóstico e estatístico de transtornos mentais. 5. ed.rev. - Porto Alegre: Artmed, 2014.

BRASIL. MEC/SEsu. Políticas e Programas na Educação Superior. 2007.

Lei $\mathbf{n}^{\circ}$ 9.394, de 20 de dezembro de 1996. Estabelece as diretrizes e bases da educação nacional. Brasília, 20 de dezembro de 1996. Disponível em: http://portal.mec.gov.br/arquivos/pdf/ldb. pdf. Acesso em: 17 de abril. 2018.

Ministério da Educação. Decreto no 7.611/2011, de 17 de novembro de 2011. Diário Oficial da União, Brasília, DF, 2011.

Ministério da Educação. Secretaria de Educação Especial. Política Nacional de Educação Especial na Perspectiva da Educação Inclusiva - Brasília: MEC/SEESP, 2008.

Ministério das Relações Exteriores. Decreto no 6.949/2009, de 25 de agosto de 2009. Diário Oficial da União, Brasília, DF, 2009.

Presidência da República. Lei no 7.234, de 19 de julho de 2010. Programa Nacional de Assistência Estudantil (PNAES). Brasília, DF: MEC, 2010.

. Ministério da Educação. Ministério da Justiça e Cidadania. Lei no 13.409, de 28 de dezembro de 2016. Diário Oficial da União, Brasília, DF, 2016.

BUYTENDORP. Adriana Aparecida Burato Marques. Currículo em Educação Especial: o Texto as Imagens e o Acesso ao Ensino. Dissertação (Mestrado em Educação) Programa de Pós-Graduação em Educação - Universidade Federal de Mato Grosso do Sul - (UFMS). Campo Grande 2006.

DIVISÃO. Relatório de atividades - 2015; dez. 2015.

GIL, Antonio Carlos. Como elaborar projetos de pesquisa. 4.ed. - São Paulo: Atlas, 2002.

GRAMSCI, A. Concepção dialética da história. R de Janeiro, Civilização Brasileira, 1978.

LUCKESI, Cipriano. Avaliação da Aprendizagem Escolar. Editora Cortez, 2005.

MACIEL, C. E.; ANACHE, A. A. A permanência de estudantes com deficiência nas universidades. Educar em Revista, Curitiba, Brasil, v. 33, n. especial 3, p. 71-86, dez. 2017. 
MACIEL, C. E.: URQUIZA, A. H. A. Inclusão e Direitos Humanos nas Políticas de Educação Superior. In: JEZINE, E.; BRANCO, U. V. C. (Org.). Educação Superior: saberes, tecnologias e desafios para a formação. 1ed. João Pessoa: CCTA, 2017.

MANJÓN, D. G. Adaptaciones Curriculares; Guia para Su Elaboración. 2ª ed. Málaga: Aljibe,1995.

MÉSZÁROS, István. A educação para além do capital. São Paulo: Boitempo, 2005.

MIRANDA, T.G. A inclusão de pessoas com deficiência na universidade. In: JESUS, D.M;

BAPTISTA, C.R; BARRETO, M.A.S.C; VICTOR, S.L. Inclusão práticas pedagógicas e trajetória de pesquisa. Porto Alegue: Editora Mediação, 2011, p.120.

ORGANIZAÇÃO DAS NAÇÕES UNIDAS (ONU). Convenção sobre os Direitos das Pessoas com Deficiência. Brasília, DF: ONU, 2006.

SANTANA. Leila Lima De Souza. Acesso e Permanência na Educação Superior - estratégias e ações da divisão de acessibilidade e ações afirmativas/ DIAF na UFMS. Dissertação (Mestrado em Educação) Programa de Pós-Graduação em Educação (PPGEdu) - Universidade Federal de Mato Grosso do Sul (UFMS). Campo Grande, 2016, p.120.

SANTOS, B. de S. A Universidade do século XXI. Para uma reforma democrática e emancipatória da Universidade. $2^{\mathrm{a}}$ ed., v. 120. São Paulo: Cortez, 2005.

SAVIANI, D. (1991). Pedagogia histórico-crítica: primeiras aproximações. 2. ed. São Paulo, Cortez e Autores Associados.

SILVA, Tomaz Tadeu. Identidades terminais: as transformações na política da pedagogia e na pedagogia da política. Petrópolis, RJ: Vozes, 1996.

UNIVERSIDADE. Projeto Pedagógico Institucional da Fundação Universidade Federal de Mato Grosso do Sul (PPI/UNIVERSIDADE). Disponível em: <https://faeng.ufms.br/files/2014/11/PPI UFMS_2009.pdf> Acesso em 20 abril de 2018.

UNIVERSIDADE. Plano de Desenvolvimento Institucional da Fundação Universidade Federal de Mato Grosso do Sul (PDI/UNIVERSIDADE). Disponível em: <https://faeng.ufms.br/files/2017/08/ PDI-Plano-de-Desenvolvimento-Institucional-da-UFMS_2015-2019.pdf $>$ Acesso em 20 abril de 2018.

Relatório de Gestão. UNIVERSIDADE. Disponível em: <http://www-new.ufms.br/wpcontent/uploads/2015/12/relatorio_de_gestao_2008, 2009, 2010, 2011, 2012, 2013, 2014, 2015 E 2016.pdf 